\title{
Evaluation of boron industrial solid waste in composite materials
}

\section{Demet Topaloğlu Yazııı ${ }^{\mathrm{a}}$ and Hayrullah Çetinkaya ${ }^{\mathrm{b}}$}

${ }^{a}$ Faculty of Engineering and Architecture, Department of Chemical Engineering, Eskişehir Osmangazi University, Eskişehir, Turkey; ${ }^{b}$ Faculty of Engineering, Department of Chemical Engineering, Izmir Institute of Technology, Izmir, Turkey

\section{ABSTRACT}

Boron industrial solid waste is used as reinforcement for preparing composite materials. This waste has boron trioxide which holds unique properties may affect the surface or interface of the composite. The prepared composites are characterized in order to determine the dispersion and the structure by means of inverse gas chromatography (IGC), Fourier transform infrared spectroscopy, thermal gravimetric analysis, scanning electron microscopy (SEM) and X-ray diffraction (XRD). There is a strong relation between the dispersion of reinforcement and the properties of newly formed composite. The dispersive component of the surface energies of the composites and components are determined by IGC. This parameter is difficult to measure by other methods and it is related to the wettability and adhesive characters of solid materials. The effect of compounding ratios of reinforcement is also examined. Furthermore, XRD diffractograms and SEM images of composites showed well dispersion. Thermal analysis revealed that the addition of the boron industrial solid waste to the polymer increased the thermal stability of pure polymer. Infrared spectra of the composites indicated that the composites were formed from the waste reinforcement and the polymer matrix.

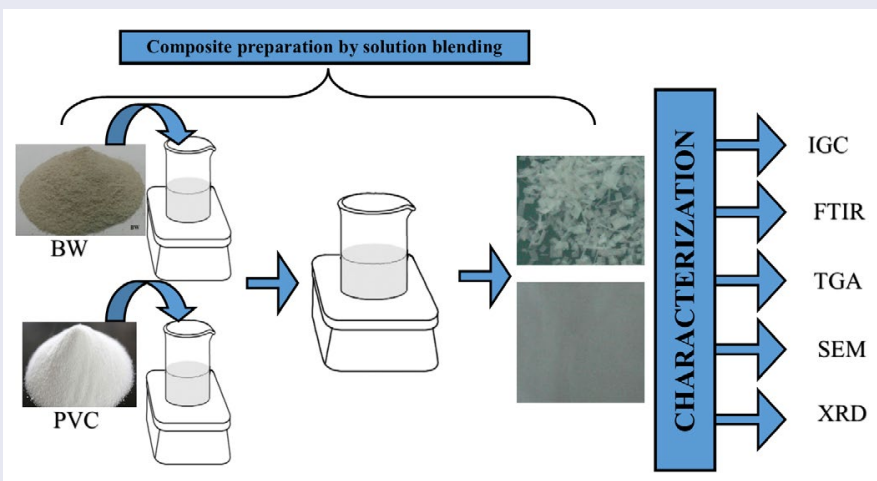

\section{ARTICLE HISTORY}

Received 12 January 2017

Accepted 22 March 2017

\section{KEYWORDS}

Boron waste; inverse gas chromatography; surface characterization; composite 


\section{Introduction}

Nowadays, the tendency of the material technologies is to product advanced composite materials. Polymer-clay composites among these new materials attract attention of both researchers in academic and industrial areas, because of being cheap and having easy preparation techniques. Industrially active usage of the polymer composites is closely related to the polymer-clay interaction. The polymer-clay interaction depends on the textural, structural and physico-chemical interfacial properties of clays [1]. Interfacial properties, such as adhesion, play an important role in the performance of components in many areas including the electronics, automotive, aerospace, and biomedical industries. Accordingly, it is desirable to find ways to enhance the strength of polymer interfaces while maintaining characteristic bulk properties for a given application [2]. It is also desirable to find materials which are compatible with each other. If the composite components (the polymer and the reinforcement) are not compatible, a surfactant should be added to compound the components. This will increase the production steps and the cost of the product. So the researchers are willing to search less chemical including processes and cheap materials. This idea directed this study towards preparing polymer composites with boron industrial solid waste. It is the waste of Borax Plants and forms huge amounts during the production. This waste also called as clay waste or borax slime, is containing $19.44 \% \mathrm{~B}_{2} \mathrm{O}_{3}$ and it is discharged into the ponds having an area bigger than the plant area [3]. Increased environmental awareness has led to a demand for recycling this waste like using it in the production of cement, ceramic, and as a fertilizer [3,4]. Despite these increasing numbers of studies in academic and industrial researches, the subject of preparing polymer composites reinforced with this waste has remained elusive. This study has focused on preparing composites of this waste without using any surfactant. Adhesion is one of the specific unique properties of this waste content. This property promoted this study to investigate the surface of composites and composite components by inverse gas chromatography (IGC) via calculating the dispersive component of the surface energies. The effect of compounding ratios of composites is also examined. Besides this, the prepared composites are characterized by using the Fourier transform infrared spectroscopy (FTIR), X-ray diffraction (XRD), scanning electron microscopy (SEM), thermogravimetric analysis.

\section{Materials and methods}

The matrix used while preparing the composites is PVC (Fluka, $M_{w} \sim 48,000$, density: $1.4 \mathrm{~g} /$ $\left.\mathrm{ml}\left(25^{\circ} \mathrm{C}\right)\right)$. The reinforcement material is the solid waste of Eti Maden Kurka Boron Plant in Turkey. The chemical composition of the solid waste is as follows: $19.44 \% \mathrm{~B}_{2} \mathrm{O}_{3}, 16.85 \%$ $\mathrm{CaO}, 13.01 \% \mathrm{MgO}, 9.82 \% \mathrm{SiO}_{2}, 10.30 \% \mathrm{Na}_{2} \mathrm{O}, 1.30 \% \mathrm{Al}_{2} \mathrm{O}_{3}, 1.49 \% \mathrm{Fe}_{2} \mathrm{O}_{3}, 1.01 \% \mathrm{~K}_{2} \mathrm{O}$, and $26.78 \% \mathrm{H}_{2} \mathrm{O}$ [3]. The average particle size of the waste is in the range of 224-300 $\mu \mathrm{m}$. Tetrahydrofuran (\% 99, Merck) is used to dissolve the polymer. The adsorbates (probes) used for IGC studies are n-hexane, n-heptane, n-octane, n-nonane, n-decane ( $\geq 99 \%$, Merck, reagent grade).

\subsection{Polymer composite preparation}

Polymer composites have been prepared with varying loading (compounding) ratios (w/w: 5,10 and 20\%) of boron industrial solid waste and polyvinylchloride by using solvent 
intercalation method. After that, the composites will be designated as: BWPC5 (Boron industrial solid waste-Polymer Composite w/w: 5\%), BWPC10, BWPC20. The mixtures of reinforcement and polymer are prepared separately and mixed at $800 \mathrm{rpm}$. The reinforcement is added slowly to the polymer, mixed at $800 \mathrm{rpm}$, agitated at $40{ }^{\circ} \mathrm{C}$ in ultrasonic bath. They are poured in to the drying pools and dried at room temperature. Prepared composite materials are grinded by using Retsch Cryomill.

\subsection{Characterization}

The chromatographic experiments are performed with Agilent 7890 gas chromatograph equipped with a flame ionization detector (FID). A stainless steel column ( $2 \mathrm{~m}$ long and $5.35 \mathrm{~mm}$ ID) previously washed with methanol and acetone is packed with about $2 \mathrm{~g}$ of each solid sample. The adsorbents are conditioned at $70^{\circ} \mathrm{C}$ in the nitrogen gas flow for $4 \mathrm{~h}$ prior to the measurements. The flow rate of the nitrogen is $40 \mathrm{~mL} / \mathrm{min}$. The experiments are carried out within the temperature range of $40-70^{\circ} \mathrm{C}$ for each solid. The temperature is $150{ }^{\circ} \mathrm{C}$ for injector and $200^{\circ} \mathrm{C}$ for detector. Retention time is obtained from the difference of the peak maxima and the methane marker. FTIR spectra of the materials are recorded with Digilab Excalibur series Fourier Transform Infrared spectrometer with Harrick Praying Mantis TM DRIFT (Diffuse reflectance infrared Fourier transform spectroscopy) accessory in the range of $4000-400 \mathrm{~cm}^{-1}$, and 32 scans are taken at 2 resolutions. The spectrometer was calibrated using polystyrene and $\mathrm{CO}_{2}$ bands. Kubelka-Munk function is used to display the DRIFT spectrum. Materials are diluted with $\mathrm{KBr}(\mathrm{w} / \mathrm{w} ; 3 / 100)$ and finely powdered $\mathrm{KBr}$ is used as reference. The thermal analyses of the composites and the composite components are done by Perkin Elmer Diamond model thermal gravimetric analysis (TGA) instrument. Each analysis is conducted at air atmosphere and a heating rate of $10^{\circ} \mathrm{C} / \mathrm{min}$. The temperature range is $30-1000{ }^{\circ} \mathrm{C}$ for the reinforcement and $30-700{ }^{\circ} \mathrm{C}$ for the other materials. The surface micrographs of gold coated materials are recorded by SEM, using JEOL JSM-5600 LV instrument. The XRD diffractograms are obtained by Rigaku Rint 2000 powder diffractometer and they are measured at $2 \theta$, in the range of $2^{\circ}-12^{\circ}$, using a $\mathrm{Cu}-\mathrm{Ka}$ incident beam $(\lambda=0.154059 \mathrm{~nm})$, monochromated. The scanning speed is $1 \% \mathrm{~min}$. The voltage and the current of the X-ray tubes are $40 \mathrm{kV}$ and $30 \mathrm{~mA}$, respectively.

\section{Results and discussion}

The surface morphology and the thermal behaviors of composites are some of the common methods that are used to investigate the interaction characteristics between the reinforcement and the matrix. Considering this, the surface morphology and the thermal behaviors of these new composites are examined. Additionally, using IGC and DRIFT methods improved the evaluation of the characteristics of these new materials. The results of IGC analysis, DRIFT spectra, thermal analysis, SEM images and XRD diffractograms of composite components and the composites are given respectively.

\subsection{Inverse gas chromatography}

IGC is a well known surface analysis method over the past decades. The surface free energy is one of the parameter that can be determined by IGC. The strength of interaction between 
inorganic fillers and reinforcements depends on the surface free energy of the components [5]. Especially, explaining this surface physicochemical property of components give an insight to the wettability and adhesive characters of a composite material. It is known that the dispersion of reinforcement in a polymer matrix is affected by the surface energy $[6,7]$. In adhesion and composite material studies, IGC is generally carried out at infinite dilution, so that the probe-probe interactions are negligible and the retention time is governed by solid-probe interactions only $[8,9]$. The net retention volume $\left(V_{N}\right)$ is the key parameter to calculate other physicochemical parameters. The relation between the net retention volume and the dispersive component of the surface energy $\gamma_{\mathrm{S}}^{\mathrm{d}}$ is as follows:

$$
R T \operatorname{Ln} V_{N}=2 N \cdot\left(\gamma_{S}^{\mathrm{d}}\right)^{1 / 2} \cdot a \cdot\left(\gamma_{\mathrm{L}}^{\mathrm{d}}\right)^{1 / 2}+\text { constant }
$$

Here, $W=2\left(\gamma_{S}^{\mathrm{d}} \cdot \gamma_{\mathrm{L}}^{\mathrm{d}}\right)^{1 / 2}$ is the work of adhesion, $W$ of a non-polar liquid onto a solid can be expressed as the geometric mean of the dispersive components of the solid $\left(\gamma_{S}^{\mathrm{d}}\right)$ and the liquid $\left(\gamma_{\mathrm{L}}^{\mathrm{d}}\right)$. The detailed theoretical background is given elsewhere [10].

In this study, the $\gamma_{S}^{\mathrm{d}}$ values obtained for the composite components and the composites are listed in Table 1. Dispersive interactions within the surface activities decreased with increasing temperature. The $\gamma_{\mathrm{S}}^{\mathrm{d}}$ values for the composites increased with the increasing ratio of reinforcement.

Figure 1 depicts a plot of $\gamma_{\mathrm{S}}^{\mathrm{d}}$ versus temperature for the composite components and the composites. Usually, the variation of $\gamma_{S}^{\mathrm{d}}$ as a function of temperature is linear [11] and hence at low temperatures it can be obtained by extrapolation [8]. Assuming such a linear correlation in this study, the extrapolated values of $\gamma_{\mathrm{S}}^{\mathrm{d}}$ for the composite components and the composites at room temperature are as follows: $63.0 \mathrm{~mJ} / \mathrm{m}^{2}$ for BW, $32.5 \mathrm{~mJ} / \mathrm{m}^{2}$ for PVC, $33.9 \mathrm{~mJ} / \mathrm{m}^{2}$ for BWPC5, $43.1 \mathrm{~mJ} / \mathrm{m}^{2}$ for BWPC10 and $45.8 \mathrm{~mJ} / \mathrm{m}^{2}$ for BWPC20. The dispersive component of surface energy of composites lay between the components.

The dispersive component of surface energy of PVC is calculated by Uhlmann and Schneider [12] with a different method and found as $32 \mathrm{~mJ} / \mathrm{m}^{2}$ at $45^{\circ} \mathrm{C}, 31 \mathrm{~mJ} / \mathrm{m}^{2}$ at $45^{\circ} \mathrm{C}$ with Dorris-Gray method by Chehimi et al. [13], $32.4 \mathrm{~mJ} / \mathrm{m}^{2}$ at $50{ }^{\circ} \mathrm{C}$ with Dorris-Gray method by Slimane et al. [14], $30.7 \mathrm{~mJ} / \mathrm{m}^{2}$ at $50{ }^{\circ} \mathrm{C}$ by Rocha et al. [15]. In this study, $\gamma_{\mathrm{S}}^{\mathrm{d}}$ value of PVC is also calculated by Dorris-Gray method and found as $31 \mathrm{~mJ} / \mathrm{m}^{2}$ at $40{ }^{\circ} \mathrm{C}$. It is consistent with the literature data. As far as we know, there is no report for this solid waste in the literature about defining the $\gamma_{\mathrm{S}}^{\mathrm{d}}$ values by IGC method.

It is known that a surfactant is applied to the reinforcement in order to enhance the compatibility between the reinforcement and the matrix while preparing polymer composites. The surfactant also enhances the dispersion of the reinforcement in polymer matrix. This surfactant is usually an organic cation. The surface of the reinforcement becomes hydrophobic and the surface energy of the reinforcement is reduced by applying this surfactant so, the surface energy of the reinforcement is comparable with the polymer. $\gamma_{S}^{\mathrm{d}}$ value

Table 1. Values of $\gamma_{S}^{d}$ for the composite components and the composite.

\begin{tabular}{lccccc}
\hline & \multicolumn{5}{c}{$\gamma_{\mathrm{S}}^{\mathrm{d}}\left(\mathrm{mJ} / \mathrm{m}^{2}\right)$} \\
\cline { 2 - 6 }$T\left({ }^{\circ} \mathrm{C}\right)$ & BW & PVC & BWPC5 & BWPC10 & BWPC20 \\
\hline 40 & 57.1 & 29.5 & 31.2 & 39.1 & 43.8 \\
50 & 55.5 & 28.8 & 30.1 & 37.1 & 42.6 \\
60 & 51.5 & 27.4 & 29.2 & 34.7 & 41.7 \\
70 & 49.2 & 25.4 & 27.2 & 33.2 & 40.7 \\
\hline
\end{tabular}




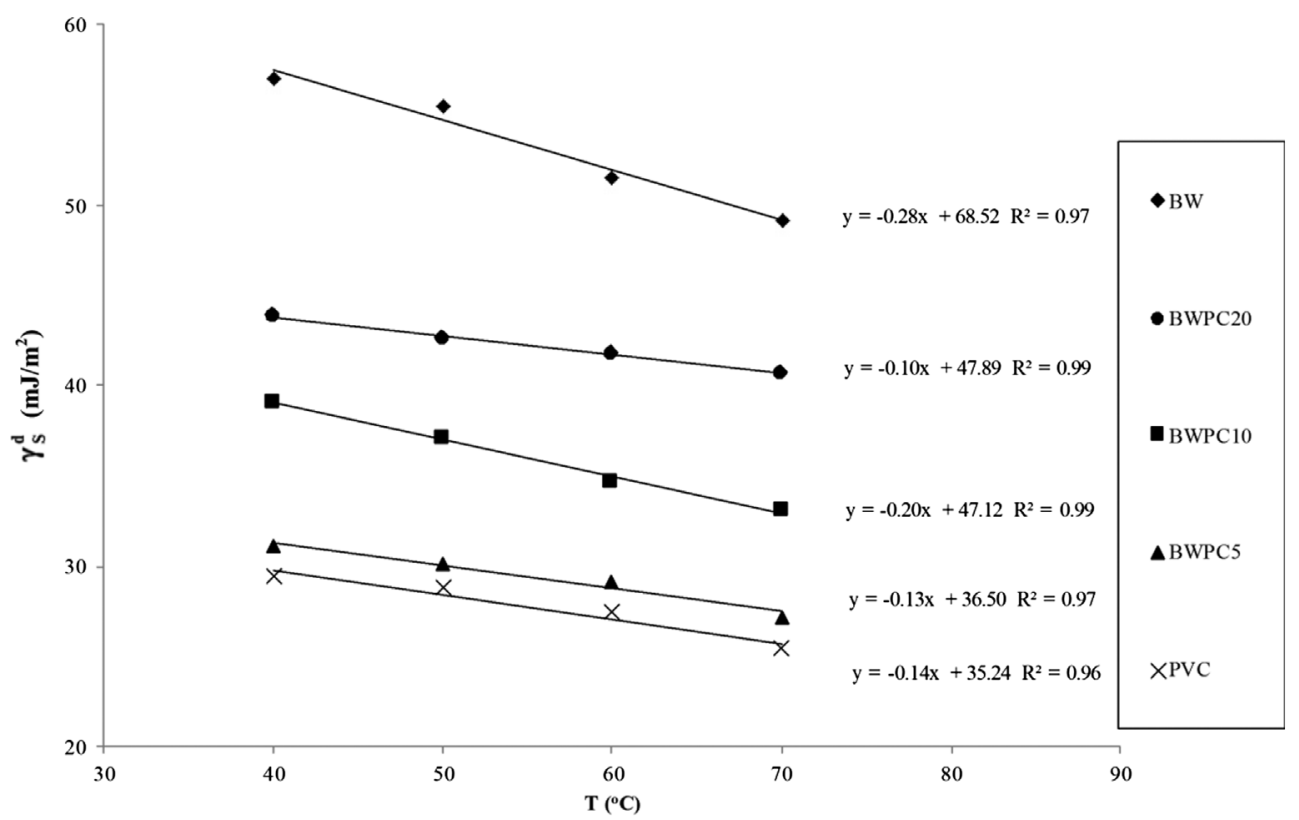

Figure 1. Plot of $\gamma_{s}^{d}$ versus temperature for the composite components and the composites.

provides an insight about the dispersion. In this study the obtained $\gamma_{\mathrm{S}}^{\mathrm{d}}$ value at $70{ }^{\circ} \mathrm{C}$ for the reinforcement is $49.2 \mathrm{~mJ} / \mathrm{m}^{2}$. Considering the similarity of the chemical composition of reinforcement to the clays, the $\gamma_{S}^{\mathrm{d}}$ values of clays determined by IGC are collected from the literature. The values are as follows: $84 \mathrm{~mJ} / \mathrm{m}^{2}$ at $320^{\circ} \mathrm{C}$ for sepiolite clay [16], $155 \mathrm{~mJ} /$ $\mathrm{m}^{2}$ at $100{ }^{\circ} \mathrm{C}$ for bentonite clay [17], $216 \mathrm{~mJ} / \mathrm{m}^{2}$ at $150{ }^{\circ} \mathrm{C}$ for montmorillonite clay [18], $139 \mathrm{~mJ} / \mathrm{m}^{2}$ at $80^{\circ} \mathrm{C}$ for kaolin [19], $164 \mathrm{~mJ} / \mathrm{m}^{2}$ at $130^{\circ} \mathrm{C}$ for attapulgite clay [20]. These $\gamma_{\mathrm{S}}^{\mathrm{d}}$ values obtained for the clays that are not modified by a surfactant are higher than the reinforcement used in this study. $\gamma_{\mathrm{S}}^{\mathrm{d}}$ values of the modified reinforcements are found lower and closer to the values of polymers in the literature $[7,18,19]$. The closer values are mentioned as an enhancing parameter for the dispersibility of the reinforcement [21]. $\gamma_{S}^{\mathrm{d}}$ value of this reinforcement which is boron industrial solid waste is found closer to the polymer. This idea motivated the study to evaluate the performance of the composites prepared without doing any modification to the reinforcement. This prevents both the loss of the boron trioxide amount in the industrial solid waste and any additional step for alteration the surface and the interface of the waste.

\subsection{DRIFT spectra}

The DRIFT spectra of the composite components (BW and PVC) and the composites are given in Figures 2-4, respectively.

In the Figure 2, the broad peak between 3700 and $2700 \mathrm{~cm}^{-1}$ wave numbers is due to the $\mathrm{X}-\mathrm{H}$ region and it is attributed to the $\mathrm{O}-\mathrm{H}$ stretching vibration [22]. BW has dolomite $\left(\mathrm{CaMg}\left(\mathrm{CO}_{3}\right)_{2}\right)$, searlesite $\left(\mathrm{NaBSi}_{2} \mathrm{O}_{5}(\mathrm{OH})_{2}\right)$ and calcite $\left(\mathrm{CaCO}_{3}\right)$ minerals in its structure. The peaks at 887 and $710 \mathrm{~cm}^{-1}$ are originated from the structure of calcite. The peak at 


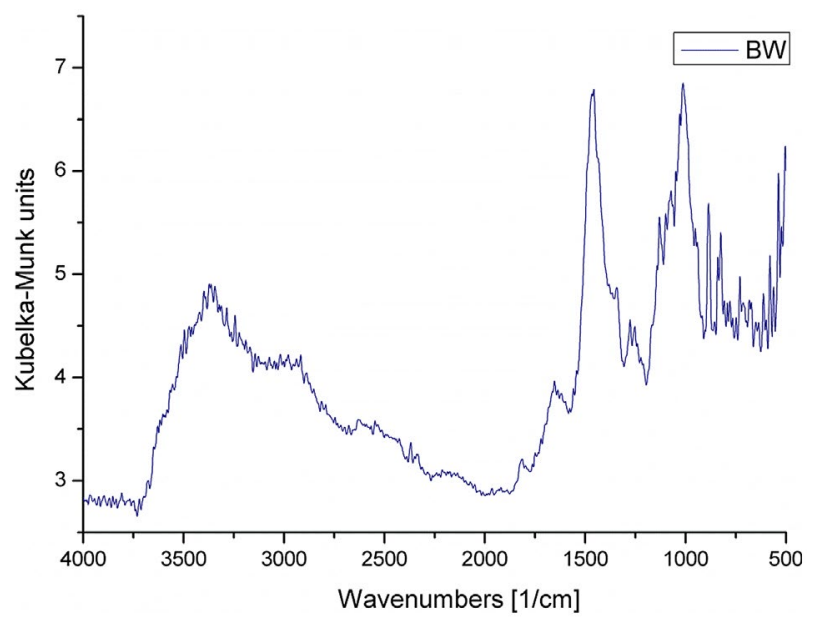

Figure 2. DRIFT spectrum of BW.

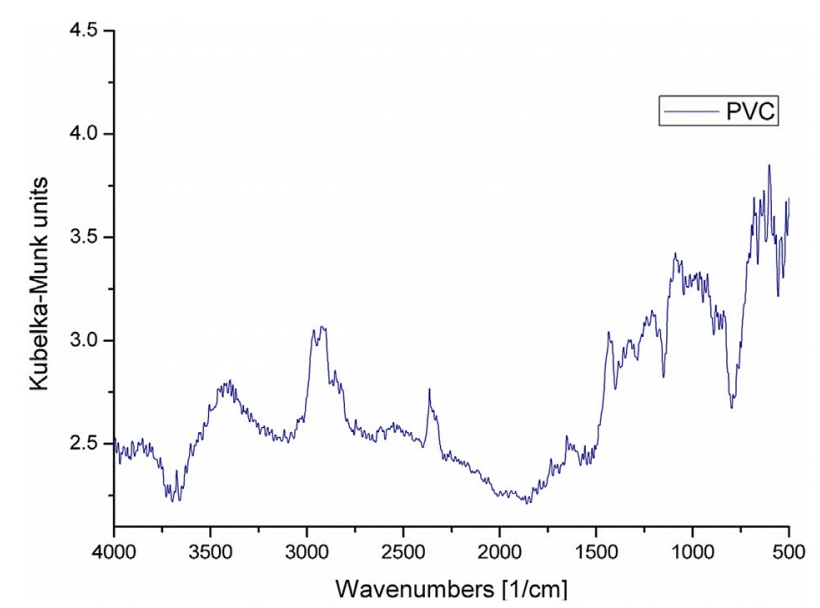

Figure 3. DRIFT spectrum of PVC.

$1457 \mathrm{~cm}^{-1}$ is related to the stretch vibrations of $\mathrm{C}=\mathrm{O}$ group due to calcite impurity, it is confirming the presence of carbonate in the waste [23]. The peaks between the wave numbers of 1380 and $1310 \mathrm{~cm}^{-1}$ are assigned to the stretching of $\mathrm{B}-\mathrm{O}$ bond. The peak at $825 \mathrm{~cm}^{-1}$ is due to the bond of $\mathrm{B}-\mathrm{OH}[24]$.

In the Figure 3, the peaks at $2950-2850 \mathrm{~cm}^{-1}$ are due to the stretching of $\mathrm{C}-\mathrm{H}$ bonds, the peaks at 1430 and $1330 \mathrm{~cm}^{-1}$ are due to the in-plane bending of the $\mathrm{C}-\mathrm{H}$ bonds and the peak at $1262 \mathrm{~cm}^{-1}$ is due to the $\mathrm{C}-\mathrm{H}$ rocking in the structure of PVC [25]. The peaks between 800 and $600 \mathrm{~cm}^{-1}$ are originated from the stretching of $\mathrm{C}-\mathrm{Cl}$ [26].

In the Figure 4, the stretching of $\mathrm{C}-\mathrm{H}$ bonds at 1430 and $1330 \mathrm{~cm}^{-1}$ observed for PVC can be seen for all composites. The peaks at 1816 and $1653 \mathrm{~cm}^{-1}$ observed for BW also occurred in composites and the intensities of these peaks increased with increasing the percent of BW in the composite. These indicated that the composites formed from the polymer matrix and the reinforcement material. 


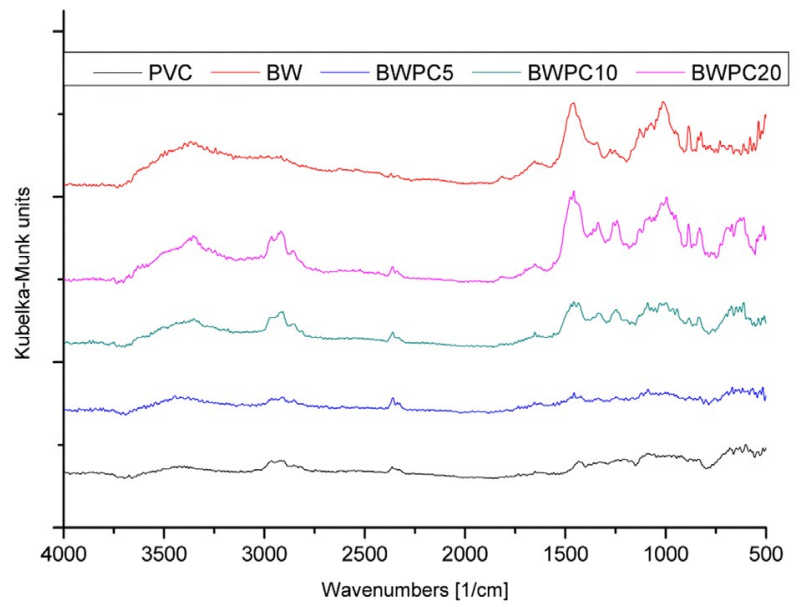

Figure 4. DRIFT spectra of composite components and composites.

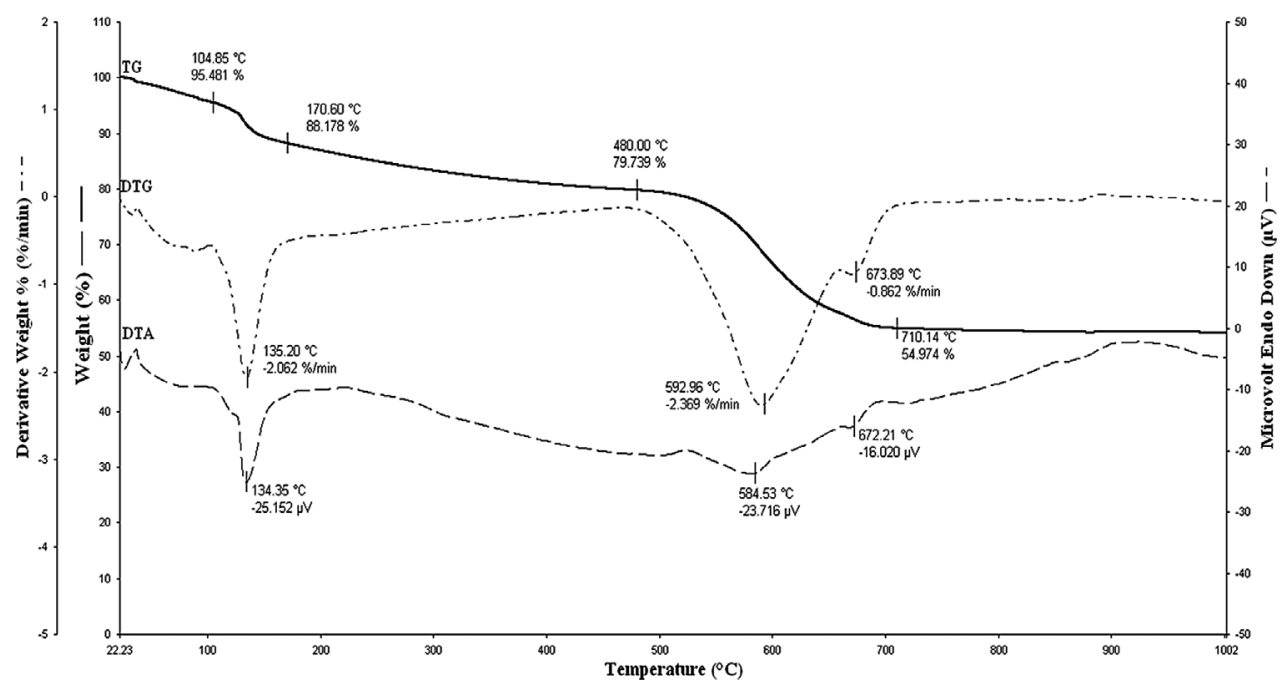

Figure 5. The TG, DTG and DTA curves of BW.

\subsection{Thermal analysis}

Thermal analysis (TG, DTG and DTA) has been used to determine the thermal properties of composite components and its composites. Thermogravimetric behavior can be used also as a proof of the interactions between the organic medium and inorganic reinforcement's surface [27].

The TG, DTG and DTA curves of composite components are given in Figures 5 and 6.

In Figure 5, three degradation steps are seen. The first weight loss of $4 \%$ approximately occurs around $100{ }^{\circ} \mathrm{C}$, is due to loss of adsorbed water molecules. The second weight loss of $12 \%$ is in the temperature range of $105-170{ }^{\circ} \mathrm{C}$ and this decrement ended around $480{ }^{\circ} \mathrm{C}$ with a weight loss of $20 \%$. It is attributed to the dehydroxylation of the material. The third 


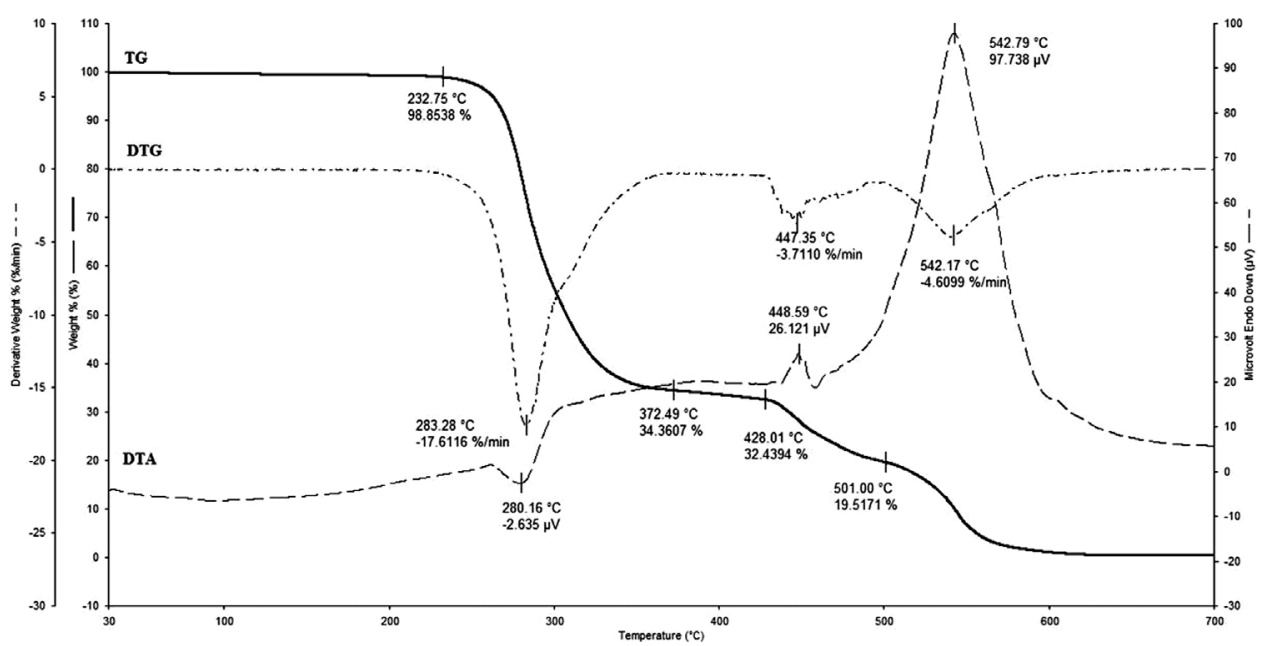

Figure 6. The TG, DTG and DTA curves of PVC.

weight loss of $45 \%$ is in the temperature range of $480-710^{\circ} \mathrm{C}$. It is due to the calcite and dolomite dissociation process that has been most probably completed [28].

In Figure 6, the first weight loss for pure PVC is observed in the temperature range of $225-360^{\circ} \mathrm{C}$, is due to the loss of $\mathrm{HCl}$. At this temperature range, the $\mathrm{Cl}$ radicals formed from the cleavage of $-\mathrm{C}-\mathrm{Cl}$ bonds and a hydrogen atom from the neighboring $\mathrm{C}-\mathrm{H}$ bond resulting in the evolution of $\mathrm{HCl}$ molecules from the polymer chain. Once the reaction is initiated, the 'allyl' activation continues and all the $\mathrm{Cl}$ atoms get dislocated along the macromolecule chain [29]. The autocatalytic effect of $\mathrm{HCl}$ accelerates the degradation. In the case of the addition of inorganic reinforcements, the degradation can be delayed by $\mathrm{HCl}$ adsorption [30]. So the thermal stability of the pure polymer can be improved by this barrier effect.

The comparison of the thermograms of the composites and the components are given in Figure 7.

The TG curve shapes of the polymer and composites are similar but the weight losses are different. The remaining weight percents of composites and the components at different temperatures are given in Table 2. The composites show an earlier weight loss. The weight losses of $2,15,5,5,8 \%$ at $250{ }^{\circ} \mathrm{C}$ are observed for polymer, reinforcement and the composites (BWPC5, BWPC10, BWPC20), respectively. Above $300{ }^{\circ} \mathrm{C}$ the weight loss of polymer is more than the composites.

Thermal stability evaluation of the composite materials can be done by comparing the temperatures which are at the same remaining weight of composites and polymer. The definition of this remaining weight is the weight of the remaining polymer which the first degradation has finished [31]. In this study; while the first degradation of polymer finished, the remaining weight of polymer is $34 \%$ and the temperature is $372{ }^{\circ} \mathrm{C}$. The temperatures at the $34 \%$ remaining weights of composites are 465,478 and $480^{\circ} \mathrm{C}$ for BWPC5, BWPC10 and BWPC20, respectively. According to these results, composites showed higher thermal stability comparing to the pure polymer. This is the result of the barrier effect of the dispersed reinforcement in the matrix $[27,32]$. TGA reveals that the thermal stability strongly depends on polymer/reinforcement interactions [27]. The temperatures at weight losses of 


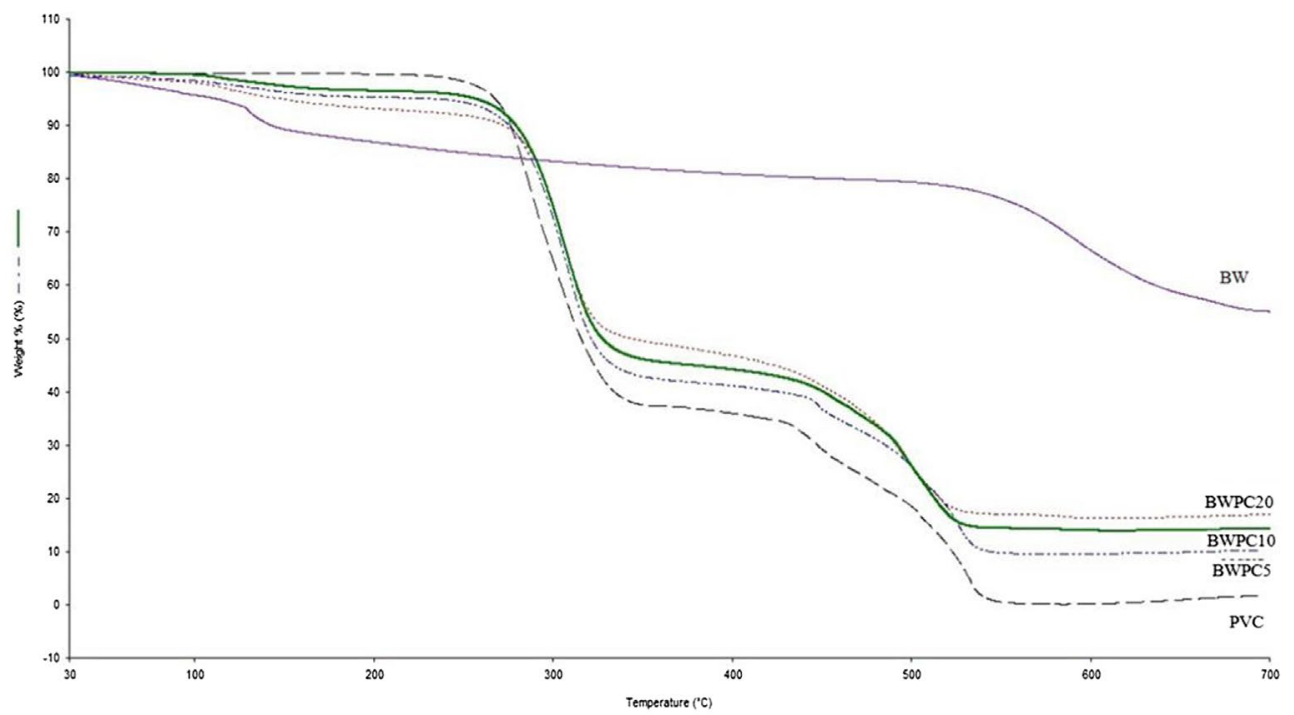

Figure 7. The comparison of the thermograms of composites and the components.

Table 2. The remaining weight percents of composites and the components at different temperatures.

\begin{tabular}{lccccc}
\hline & \multicolumn{5}{c}{ The remaining weight percents } \\
\cline { 2 - 5 } Material & $250{ }^{\circ} \mathrm{C}$ & $350^{\circ} \mathrm{C}$ & $420^{\circ} \mathrm{C}$ & $550{ }^{\circ} \mathrm{C}$ & $700{ }^{\circ} \mathrm{C}$ \\
\hline BW & 85 & 82 & 81 & 77 & 55 \\
PVC & 98 & 38 & 33 & 0 & 0 \\
BWPC5 & 95 & 43 & 40 & 10 & 10 \\
BWPC10 & 96 & 46 & 43 & 14 & 14 \\
BWPC20 & 92 & 49 & 45 & 17 & 17 \\
\hline
\end{tabular}

Table 3. The temperatures at weight losses of 50\% for composites and the components.

\begin{tabular}{lc}
\hline Material & Temperature $\left({ }^{\circ} \mathrm{C}\right)$ \\
\hline BW & Descends up to $54 \%$ \\
PVC & 315.78 \\
BWPC5 & 320.62 \\
BWPC10 & 327.57 \\
BWPC20 & 343.99 \\
\hline
\end{tabular}
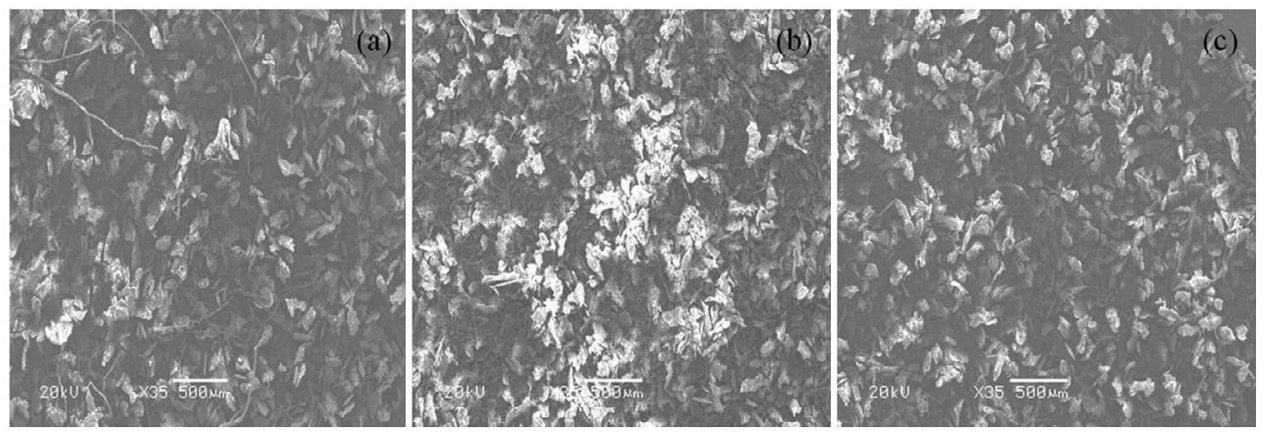

Figure 8. SEM images of (a) BWPC5, (b) BWPC10 and (c) BWPC20 at magnifications of $\times 35$. 

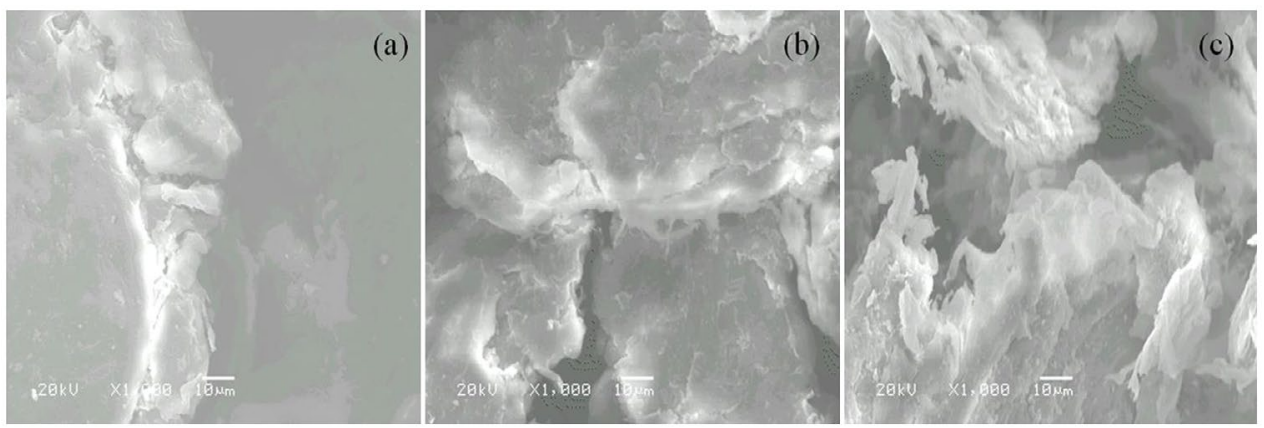

Figure 9. SEM images of (a) BWPC5, (b) BWPC10 and (c) BWPC20 at magnifications of $\times 1000$.

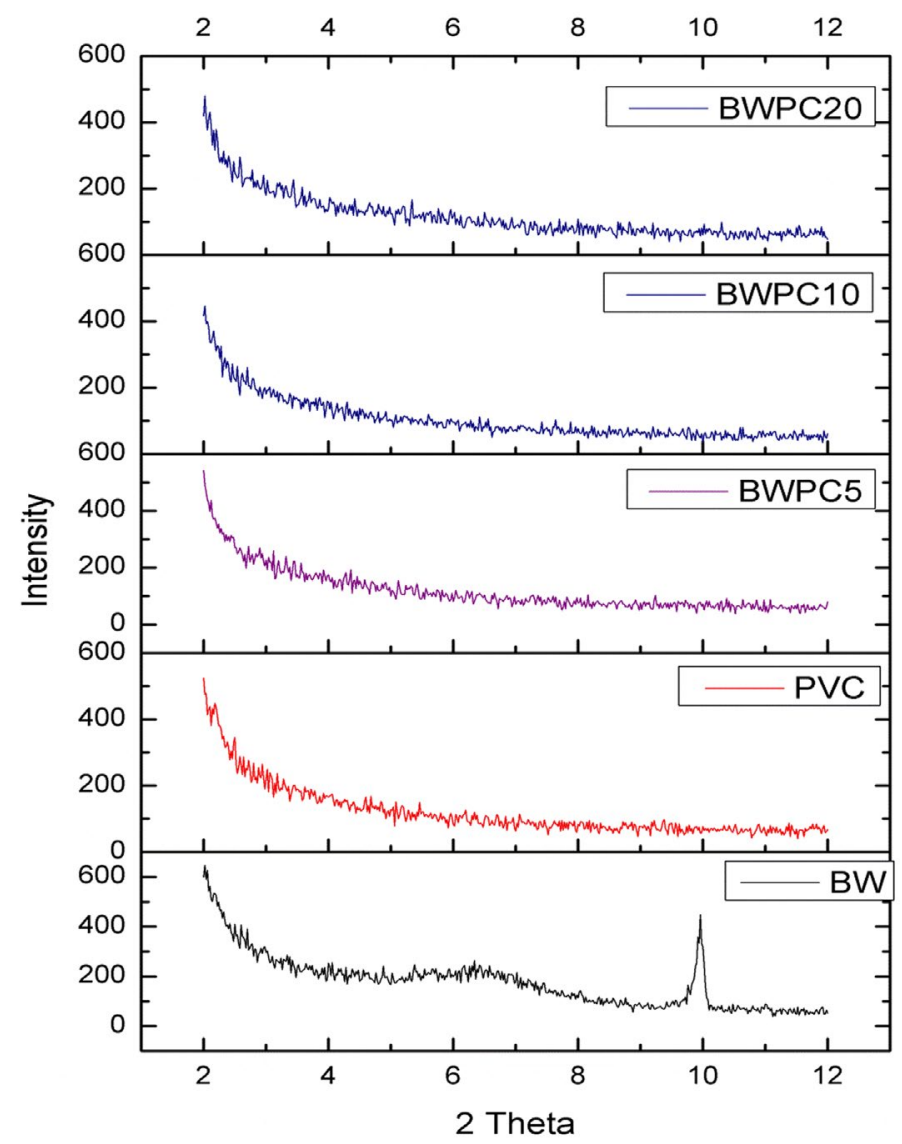

Figure 10. The XRD diffractograms between $2 \theta=2^{\circ}-12^{\circ}$ for BW, PVC, BWPC5, BWPC10 and BWPC20.

$50 \%$ are also compared in order to evaluate the effect of reinforcement addition (Table 3). The temperatures at weight losses of $50 \%$ increased with the increasing amount of reinforcement in the composites. 


\subsection{Morphologic analysis}

The morphology of the composites is evaluated by using XRD and SEM. The images of SEM give information about the reinforcement aggregates, adhesive failures and phase boundaries in composites, surface roughness, and fractured surfaces. The roughness like recesses and protrusions on the surface is very important because it intensively affects the wettability property. This property is known as the tendency of fluids to stick to the surface and can be determined by the characteristics of the surface structure [33]. In this study, SEM analysis is performed to display the surface of materials and the distribution of reinforcement in polymer matrix. The SEM images of composites are given at magnifications of $\times 35$ and $\times 1000$ in Figures 8 and 9. SEM images of BWPC5 and BWPC10 exhibit quite well dispersion. The reinforcement particles of BWPC20 are also distributed in the matrix but a few agglomerates are observed. The intensity of the little leave shapes which is the characteristic image of the reinforcement increased with the increasing reinforcement amount in the composite. Some bridges within the polymer matrix and dangling structures are also observed. The images showed that surface roughness also increased with the increasing amount of reinforcement.

Additional morphological analysis is performed by XRD analysis. The XRD diffractograms are shown in Figure 10. Two peaks are observed at $6.4^{\circ}$ and $9.9^{\circ}$ for BW and no peaks are observed for the composites although analyses are duplicated with the samples taken from the different places of composites. These results may be attributed to the good dispersion of the waste and the compounding ratio seems not to be a prominent parameter within this phenomena.

\section{Conclusions}

Boron has versatile applications depending on its unique properties. Although there are examples of boron containing polymer composites, to the best of our knowledge there have been meager researches on this boron industrial solid waste reinforced polymer composites $[34,35]$. In this study, the dispersive component of the surface energies of the composites and the components which move the tips of adhesion are determined by IGC. This method has an ability of detecting even minor changes, the difference of the compounding ratios within the composites are also examined. The $\gamma_{\mathrm{S}}^{\mathrm{d}}$ values increased with increasing compounding ratios of composites. As far as we know, there is no report in the literature about defining the $\gamma_{S}^{\mathrm{d}}$ values for this solid waste component by using IGC method. The $\gamma_{\mathrm{S}}^{\mathrm{d}}$ value of this solid waste is relatively closer to the polymer compared to the other reinforcements mentioned above. It may be affected by the boron trioxide amount in the waste. The composites were prepared by using this waste directly, without any pretreatment. Overall, this operation positively affects the production economy.

Thermal analyses showed that the thermal stabilities of the composites are better than the pure polymer. So, preparing composites with this waste improved the thermal stability of the pure polymer. The composites according to the pure polymer exhibited small amounts of weight losses at the beginning but after $300{ }^{\circ} \mathrm{C}$, this phenomenon is reversed significantly. This is accepted as an indication of the reinforcement-polymer matrix interaction. Additionally, DRIFT spectra of composites showed that the composites have been formed from this waste and PVC. SEM and XRD analyses provided a high depth of focus to the morphology and the quite well dispersions are observed. 


\section{Acknowledgement}

Authors thank Eskişehir Osmangazi University (ESOGU) for financial support. This study is the part of a project (201015040) supported by the Scientific Research Fund of Eskişehir Osmangazi University. The Eti Maden Kırka Boron Plant deserves the thanks for providing the solid boron wastes. Authors also thank Prof. Dr Güneş S. Kürkçüoğlu for the helpful suggestions regarding the interpretation of FTIR results.

\section{Disclosure statement}

No potential conflict of interest was reported by the authors.

\section{Funding}

This work was supported by the Scientific Research Fund of Eskişehir Osmangazi University [grant number 201015040].

\section{References}

[1] Annabi-Bergaya F. Layered clay minerals. Basic research and innovative composite applications. Microporous Mesoporous Mater. 2008;107(1-2):141-148.

[2] Su GM, Best K, Ranganathan T, et al. Tailored nanoparticles for enhancing polymer adhesion. Macromolecules. 2011;44:5256-5261.

[3] Özdemir M, Kıpçak İ. Boron recovery from borax sludge, boron industrial waste, by solid-liquid extraction. Ind Eng Chem Res. 2003;42:5256-5260.

[4] Celik H. Recycling of boron waste to develop ceramic wall tile in Turkey. Trans Ind Ceram Soc. 2015;74(2):108-116.

[5] Kadar F, Szazdi L, Fekete E, et al. Surface characteristics of layered silicates: influence on the properties of clay/polymer nanocomposites. Langmuir. 2006;22(18):7848-7854.

[6] Contreras V, Cafiero M, Da Silva S, et al. Characterization and tensile properties of ternary blends with PA-6 nanocomposites. Polym Eng Sci. 2006;46:1111-1120.

[7] Zhang Q, Ma X, Wang Y, et al. Morphology and interfacial action of nanocomposites formed from ethylene-vinyl acetate copolymers and organoclays. J Phys Chem B. 2009;113:11898-11905.

[8] Topaloğlu Yazıcı D. Investigating the surface properties of polymer-coated clay by IGC. Surf Interface Anal. 2010;42:974-977.

[9] Price GJ, Pastor ML, Towo AN, et al. Shear strength at Sisal fibre-polyester resin interfaces: use of inverse gas chromatography to study pretreatment effects. Compos Interfaces. 2007;14(1):21-31.

[10] Fowkes FM. Attractive forces at interfaces. Ind Eng Chem. 1964;56(12):40-52.

[11] Voelkel A, Andrzejewska E, Maga R, et al. Examination of surfaces of solid polymers by inverse gas-chromatography. 1. Dispersive properties. Polymer. 1996;37(3):455-462.

[12] Uhlmann P, Schneider S. Acid-base and surface energy characterization of grafted polyethylene using inverse gas chromatography. J Chromatogr A. 2002;969:73-80.

[13] Chehimi MM, Abel ML, Perruchot C, et al. The determination of the surface energy of conducting polymers by inverse gas chromatography at infinite dilution. Synth Met. 1999;104:51-59.

[14] Slimane B, Boukerma K, Chabut M, et al. An inverse gas chromatographic characterization of polypyrrole-coated poly(vinyl chloride) powder particles. Colloids Surf A. 2004;240:45-53.

[15] Rocha N, Gamelas JAF, Gonçalves PM, et al. Influence of physical-chemical interactions on the thermal stability and surface properties of poly(vinyl chloride)-b-poly(hydroxypropyl acrylate)b-poly(vinyl chloride) block copolymers. Eur Polymer J. 2009;45:3389-3398.

[16] Aşkın A, Topaloğlu Yazıcı D. Surface characterization of sepiolite by inverse gas chromatography. Chromatographia. 2005;61:625-631. 
[17] Hamdi B, Kessaissia Z, Donnet JB, et al. Variation de l’énergie superficielle d'une bentonite par traitement chimique et thermique [Variation of surface energy of a bentonite by chemical and thermal treatments]. Ann Chim Sci Mat. 1999;24:63-73.

[18] Mravčáková M, Boukerma K, Omastová M, et al. Montmorillonite/polypyrrole nanocomposites. The effect of organic modification of clay on the chemical and electrical properties. Mater Sci Eng C. 2006;26:306-313.

[19] Ansari DM, Price GJ. Chromatographic estimation of filler surface energies and correlation with photodegradation of kaolin filled polyethylene. Polymer. 2004;45:1823-1831.

[20] Boudriche L, Calvet R, Hamdi B, et al. Effect of acid treatment on surface properties evolution of attapulgite clay: an application of inverse gas chromatography. Colloids Surf A. 2011;392:45-54.

[21] Yang YC, Yoon PR. Examination of the surface properties of kaolinites by inverse gas chromatography: dispersive properties. Korean J Chem Eng. 2007;24(1):165-169.

[22] Ferdous D, Dalai AK, Adjaye J. A series of $\mathrm{NiMo} / \mathrm{Al}_{2} \mathrm{O}_{3}$ catalysts containing boron and phosphorus Part I. Synthesis and characterization. Appl Catal A. 2004;260:137-151.

[23] Alamin $\mathrm{AH}$, Kaewsichan L. Adsorption of $\mathrm{Pb}$ (II) ions from aqueous solution in fixed bed column by mixture of clay plus bamboo biochar. Walailak J Sci \& Tech. 2016;13(11):949-963.

[24] Gümüş OY, Ünal Hİ, Erol Ö, et al. Synthesis, characterization, and colloidal properties of polythiophene/borax conducting composite. Polym Compos. 2011;32(3):418-426.

[25] Rajendran S, Uma T. Experimental investigations on PVC-LiAsF6-DBP polymer electrolyte systems. J Power Sources. 2000;87:218-222.

[26] Garton A. Infrared Spectroscopy of polymer blends, composites and surfaces. New York (NY): Oxford University; 1992.

[27] Chrissafis K, Bikiaris D. Can nanoparticles really enhance thermal stability of polymers? Part I: An overview on thermal decomposition of addition polymers. Thermochim Acta. 2011;523:124.

[28] Kavas T, Christogerou A, Pontikes Y, et al. Production of lightweight aggregates from different types of boron wastes. Afyon Kocatepe Univ J Science. 2009;special issue:245-250.

[29] Sajini V, Paul J, Mahanta N, et al. Flexible conductive graphene/poly(vinyl chloride) composite thin films with high mechanical strength and thermal stability. Carbon. 2011;49:198-205.

[30] Karayıldırım T, Yanık J, Yüksek M, et al. The effect of some fillers on PVC degradation. J Anal Appl Pyrolysis. 2006;75:112-119.

[31] Zhu S, Zhang Y, Zhang Y, et al. Effect of $\mathrm{CaCO}_{3} / \mathrm{LiCO}_{3}$ on the $\mathrm{HCl}$ generation of PVC during combustion. Polym Testing. 2003;22:539-543.

[32] Ray SS, Okamoto M. Polymer/layered silicate nanocomposites: a review from preparation to processing. Prog Polym Sci. 2003;28:1539-1641.

[33] Sayyad Amin J, Ayatollahi Sh, Alamdari A. Fractal characteristics of an asphaltene deposited heterogeneous surface. Appl Surf Sci. 2009;256:67-75.

[34] Uygunoglu T, Gunes I, Brostow W. Physical and mechanical properties of polymer composites with high content of wastes including boron. Mater Res. 2015;18(6):1188-1196.

[35] Li D, Li Z, Zhao L. Study on EPDM/boron mud composites. Appl Mech Mater. 2013;320:358362. 